\title{
TYPE III CONGENITAL PARAESOPHAGEAL HIATAL HERNIA - A RARITY IN PEDIATRIC SURGERY. A CLINICAL CASE AND LITERATURE REVIEW
}

\author{
Stanislav Babuci ${ }^{1}$, Olga Gorbatiuc ${ }^{1}$, Alexandru Jalbă ${ }^{1}$, Victor Eremia ${ }^{1}$, Ion Negru $^{1}$, Serghei \\ Malanco ${ }^{1}$
}

\begin{abstract}
A case of type III giant paraesophageal hernia in a child of 1 year and 6 months is presented. The child was operated through superior median laparotomy and the total reduction of the stomach in the abdominal cavity, the mobilization of the hiatal defect and hernia sac with its removal were performed. The posterior cruroraphy was done with strengthening of the zone by application of the equine pericardial acellular graft fixed by interrupted sutures. The anchoring of the stomach fornix to the left hemidiaphragmatic dome (gastropexy) and $180^{\circ}$ partial anterior fundoplication were performed. The postoperative evolution was without complications and the patient was discharged in satisfactory condition on the 7 th day postoperatively. Conclusion: Using of canine pericardial acellular grafts could be a suitable option for the hiatal defect repairing in paraesophageal hiatal hernias in children, but this technique needs an adequate follow-up regimen.
\end{abstract}

Keywords: Hiatal hernia, equine pericardial acellular grafts

\section{Introduction}

Hiatal hernia $(\mathrm{HH})$ is a variant of diaphragmatic hernia, characterized by transdiaphragmatic protrusion of the abdominal organs into the posterior mediastinum through the esophageal hiatus of the diaphragm $[1,2]$. Pediatric $\mathrm{HH}$ occurs as a result of existence of the congenital diaphragmatic defect and many cases are asymptomatic [3].

Depending on the location of the gastroesophageal junction regarding diaphragm there are 4 types of $\mathrm{HH}[4,5$, 6]. Type I (85-95\%) is an axial (sliding) hernia characterized by migration of the gastric cardia into the chest cavity, lack of the Hiss angle between the stomach and the esophagus and the development of the gastroesophageal reflux disease [7, 8]. Sliding $\mathrm{HH}$ is a result of widening of the muscular hiatal channel and the circumferential laxity of the phrenoesophageal membrane [9].

Types II, III and IV are paraesophageal hernias, constituting $5-15 \%$ from the totality of $\mathrm{HH}$, which clinical significance is determined by the potential of mechanical complications $[10,11]$, although they are associated with gastroesophageal reflux too [12].Type II is a paraesophageal hernia (rolling $\mathrm{HH}$ ) characterized by normal position of gastroesophageal junction which is fixed to the preaortic fascia and median prearcuate ligament, and the hernia sac contains the gastric fornix [4, 9, 13]. Type III (mixed $\mathrm{HH}$ ) is a combination of type I and II hernias in which more than $50 \%$ of stomach is located in the mediastinum. In type IV the stomach is protruding in the mediastinum together with other abdominal organs. Along with the intrathoracic herniation of the stomach and gastroesophageal junction [14], the protrusion of duodenum, colon, omentum, spleen and pancreas could occur $[15,16,17,18,19]$.

Paraesophageal hernia is a frequent diagnosis in adults [20], however in children it could be a complication after gastroesophageal or antireflux surgery or could be of congenital origin. [21, 22].

Congenital paraesophageal hernia is a rare nosological entity in children with obscure etiology and constitutes 3,5$5 \%$ from the all $\mathrm{HH}[6,23,24,25]$. The majority of cases occur sporadically, although familial cases of paraesophageal hernia are described [26, 27]. The term "giant paraesophageal hernia" is used in cases when more than $30 \%$ of stomach migrates into the chest cavity [28, 29].

We present a case of type III paraesophageal hernia in a child of 1 year and 2 months which was incidentally discovered.

\section{Case report}

The child I.M. 1 year and 6 months old was referred to the outpatient clinic of PMSI Mother and Child Institute with a suspicion of pulmonary tumor and pneumonia. At the admission the child complained loss of appetite, frequent regurgitations, periodic postprandial agitation. The onset of that signs was 3-4 months earlier. The plain chest $\mathrm{X}$-ray in the outpatient clinic revealed a right sided cavitated mass (Fig. 1A). On upper gastrointestinal series the location of the gastroesophageal junction and a portion of stomach in the thoracic cavity was established ("sandglass sign") (Fig.1B) and the child was admitted in the "Natalia Gheorghiu" National Scientific and Practical Center of Pediatric Surgery.

${ }^{1}$ PMSI Mother and Child Institute "Natalia Gheorghiu" National Scientific and Practical Center of Pediatric Surgery E-mail: babuci@mama-copilul.md,ol.gorbatyuk@gmail.com, sandujalba@gmail.com, eremiavictor1@gmail.com, ionnegru@yahoo.com, malanco.s@gmail.com 

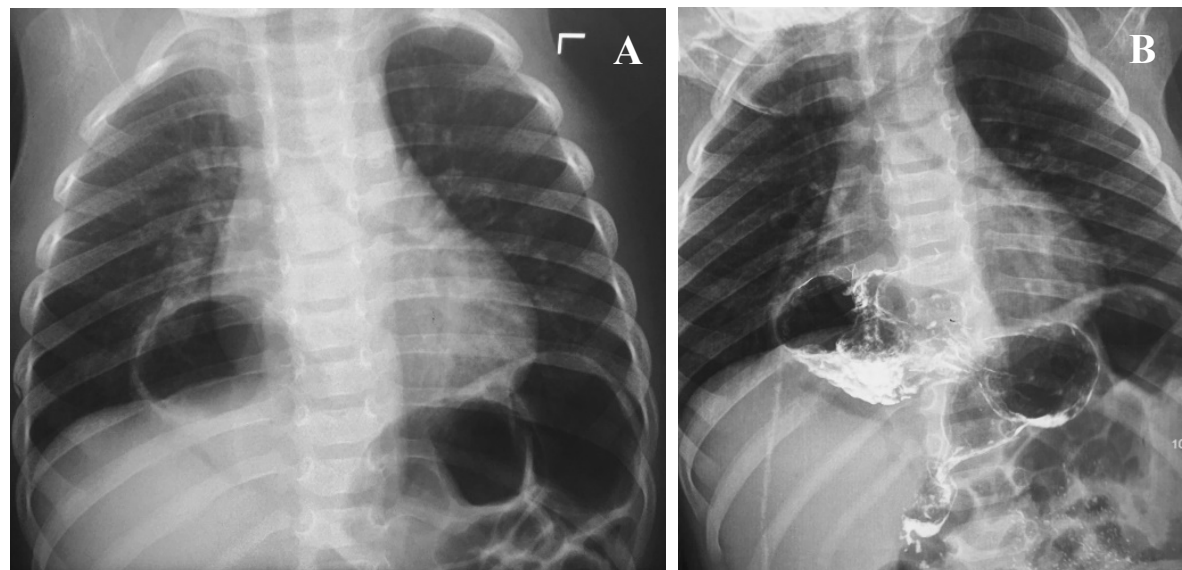

Fig. 1. Simple chest X-ray (A) - right sided intrathoracic cavitary mass.

Chest X-ray with upper gastrointestinal contrasting (B) - "sandglass" appearance of the stomach

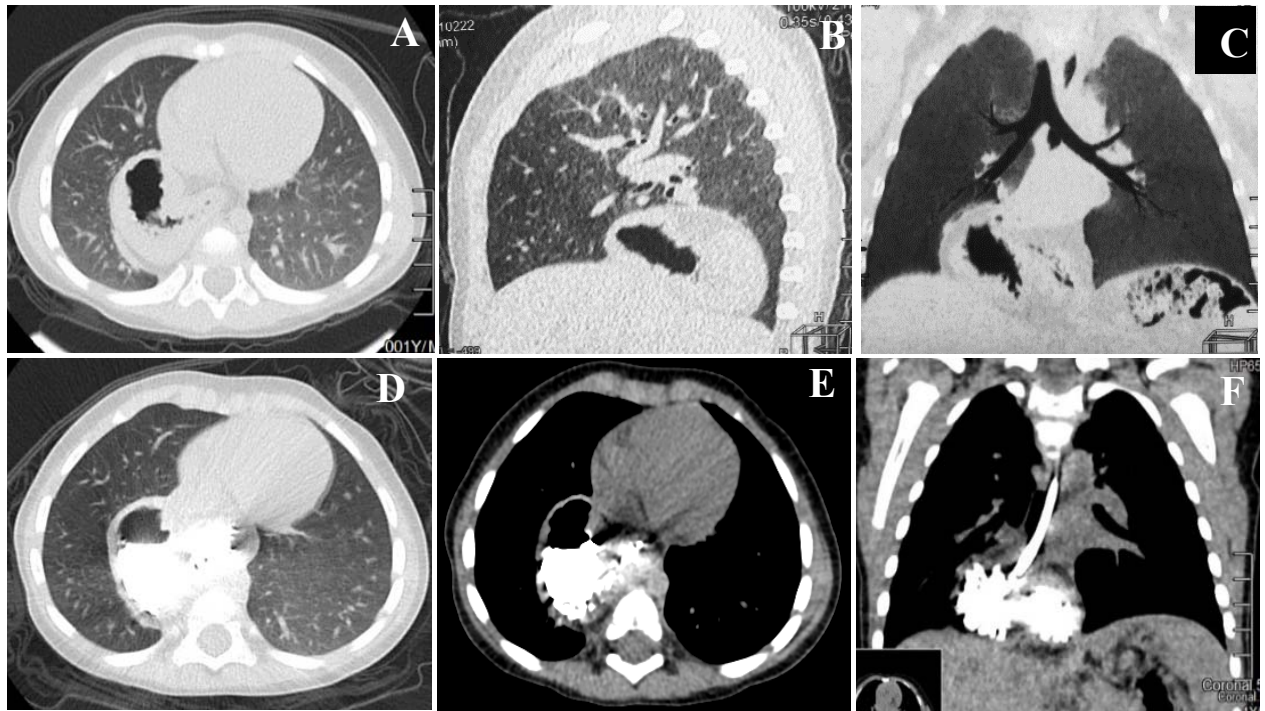

Fig. 2. Patient I.M. Computed tomography (the explanation is in the text).

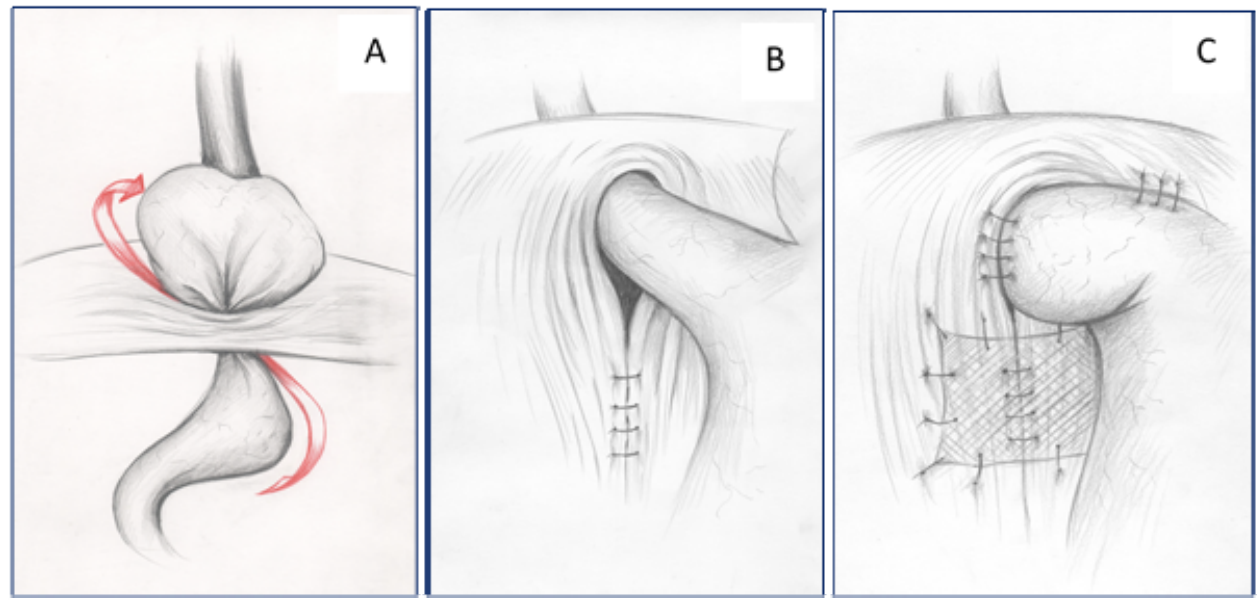

Fig. 3. Schematic presentation of paraesophageal hernia detected in patient I.M with partially intrathoracic located twisted stomach (A); B - the scheme of the curoraphy, C 


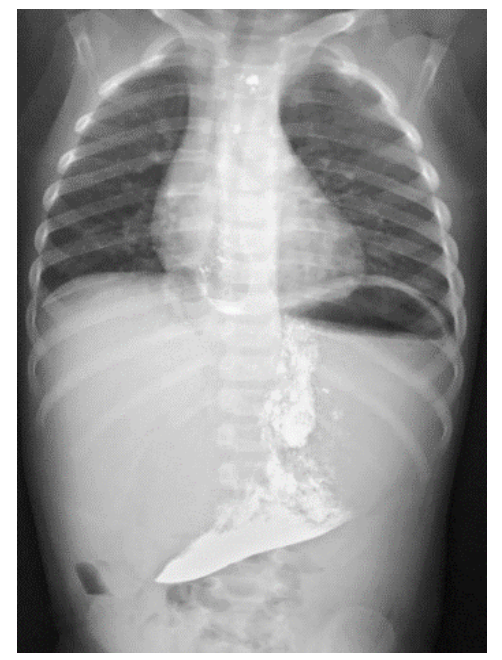

Fig. 4. Patient I.M. Chest and abdominal X-ray on the $7^{\text {th }}$ day postoperatively (the explanation is in the text).

At the admission clinical examination revealed a satisfactory general condition without deficit of body weight, the child was afebrile. From anamnestic data the child was born from the 2nd pregnancy without peculiarities. The child was born through normal vaginal delivery with a body weight of $3259 \mathrm{~kg}$ and a height of 48 $\mathrm{cm}$. There were no problems in the perinatal period. Afterwards the child development was normal, but he had repeated respiratory infections from the first months of life.

The CBC (Complete Blood Count) reveals low erythrocytes $(3,6 \times 106 / \mathrm{L})$, hemoglobin $-116 \mathrm{~g} / \mathrm{l}$, hematocrit - 34,0\%, leucocytes - 11,5x109/L. The hydroelectrolyte balance, hepatic and renal function and coagulation tests were within normal range.

The chest and abdominal simple CT scan as well as CT scan with upper gastrointestinal tract contrasting, performed for differential diagnosis, confirmed the location in the posterior mediastinum on the right side of the stomach fundus and partially of the stomach body, the diagnosis of type III paraesophageal hernia being established (Fig.2).

After preoperative preparation the abdominal cavity was opened by the superior median laparotomy. On surgical exploration the gastroesophageal junction was discovered in the chest cavity. The partially twisted stomach (the greater curvature was anteriorly located) (Fig. 3A) was also positioned in the thoracic cavity through the esophageal hiatus, which was markedly dilated. The large hernia sac was located in the chest cavity with some adhesions to the parietal pleura and pericardium.

After total reduction of the stomach into the abdominal cavity the gastrohepatic ligament was divided and the mobilization of the hiatal defect and hernia sac were performed. The hernia sac was sectioned and excised

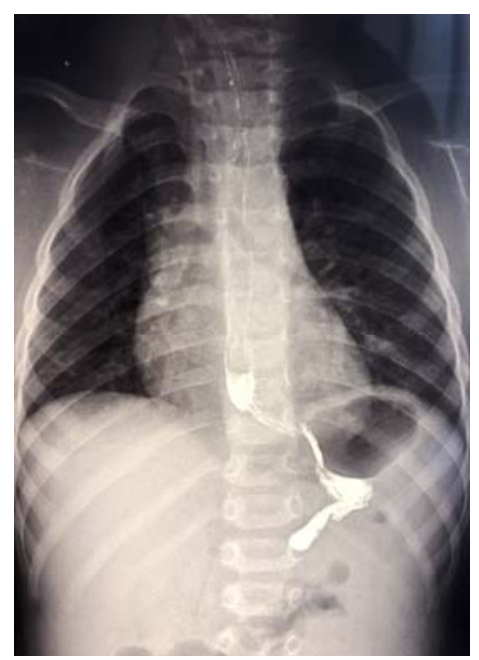

Fig. 5. Patient I.M. Chest and abdominal X-ray on the $30^{\text {th }}$ day postoperatively. excepted a small portion which was firmly fixed to the pericardium. After identification and fixation of the gastroesophageal junction the slightly dilated distal abdominal segment of the esophagus was mobilized, and the posterior cruroraphy was performed. To avoid the excessive tightening of diaphragmatic cruses and the mechanical stenosis of the esophagus in the hiatus the Collins maneuver was performed. The cruroraphy zone was enforced with equine pericardium acelular biologic graft (Bioteck Heart) fixed by interrupted sutures (Fig. 3B). Then the gastropexy by fixation of the fornix to the left hemidiaphragmatic dome and $180^{\circ}$ partial anterior fundoplication was performed.

The postoperative evolution was favorable. After hydroelectrolyte resuscitation the patient recovered without any complications and was discharged on the 7 th day postoperatively in satisfactory condition. The control X-ray on the 7 th day postoperatively revealed normal pulmonary areas without any opacities, the stomach was located below diaphragm and the esophagogastroduodenal passage was good. At the Th8 level there was a small residual space in the chest cavity, where the herniated stomach has been, but not containing contrast material (Fig.4).

\section{Discussions}

Although the first reports about congenital and posttraumatic diaphragmatic hernia occurred in XVI-XVIII centuries, the first description of the $\mathrm{HH}$ as a clinical entity was published by Henry Ingersoll Bowditch in 1853, the first operation for that type of diaphragmatic defect was performed in 1919 by Angelor Soresi [5, 29, 30]. It's worth mentioning that the first description of the $\mathrm{HH}$ was probably done by Bright in 1836, who observed at the necropsy of a 19 years old girl a portion of the stomach localized in the chest cavity, the cardia being located at the 
level of Th4 [31]. The first radiographic evidence of a stomach dislocation in the thoracic cavity belongs to Austrian clinician Hans Eppinger (1904), the term "hiatal hernia" was introduced by Ake Akerlund (1926), who also proposed the radiologic classification of this pathology [30,32].

Paraesophageal hernias in children have several components. The defect is localized at the level of esophageal hiatus, covered by peritoneal sac, which extends to the right anterior side of the esophagus, as well as to the posterior mediastinum[23,33]. During migration the stomach tends to rotate around its axis (organoaxially), that could cause a partial or complete gastric obstruction between the above located esophagus and below situated duodenum [22].

In some cases $\mathrm{HH}$ could be associated with other congenital malformations such as diaphragmatic hernias [34], pulmonary sequestration [35], pulmonary agenesis [36], gastroschisis [37], gastrointestinal malformations such as short esophagus and microgastria $[38,39]$.

Usually the paraesophageal hernias in children are characterized by asymptomatic evolution, symptomatic cases manifest itself by recurrent respiratory infections, obscure gastrointestinal symptoms and anemia [6, 24]. Regurgitations and intermittent vomiting are the most frequent symptoms in children with $\mathrm{HH}$ [14]. In some cases the evolution of the paraesophageal $\mathrm{HH}$ could be aggravated by the development of severe complications including intrathoracic gastric volvulus [26], strangulation [40], incarceration and ulceration $[4,11]$. The anemia in some cases could [41] be a manifestation of Cameron ulcer, which presents as linear lesions or erosions localized on the gastric mucosa folds at the diaphragmatic level. These lesions are determined by mechanical trauma during respiratory diaphragmatic contractions in combination with acid and ischemic injuries [42].

Prenatal diagnosis of $\mathrm{HH}$ established by ultrasound exam and MRI is of paramount importance and results in an early diagnosis of paraesophageal hernias in newborns which makes possible the surgical correction before the onset of complications [23].

In cases of paraesophageal hernias the imaging evaluation should be started with chest X-ray, which indicates the presence of abdominal organs in the thoracic cavity (usually gas bubbles). The contrast studies are performed to confirm the diagnosis and attested the full with contrast material stomach localized in the posterior mediastinum, often with an organoaxial volvulus $[10,22$, 24]. The computed tomography is used to establish the definitive diagnosis, to assess the extent of the hernia content and to reveal affected lung complications [24].

The differential diagnosis of paraesophageal $\mathrm{HH}$ should be performed with pulmonary abscesses, congenital pulmonary cysts, hydatid cysts, pericardial cysts, esophageal duplications and epiphrenic diverticulum [22].

The paraesophageal hernia in children is an absolute indication for surgery, even in cases of incidental discovering or in the neonatal period, because of the high risk of potential fatal complications $[6,10]$. There are some controversial issues regarding surgical approach in mixed paraesophageal $\mathrm{HH}$ [13]. Usually the abdominal approach through a superior median incision or right subcostal incision are preferred in children. These incisions allow an adecvated exposition of the subdiaphragmatic space. In some cases the thoracotomy could be used [22]. Lately more and more surgeons preferred the laparoscopic technique [43], even in the complicated forms of the disease [10].

Despite multiple controversies, the surgical treatment include the following elements: reduction of the hernia content into the abdominal cavity, hernia sac excision, mobilization of the distal esophagus to provide adequate length, closure of the hiatal defect, antireflux procedure and exploration for associated anomalies [24, 44].

Enforced hiatoplasty with synthetic or biologic protein grafts in paraesophageal hernias is an attractive option, with the aim to provide an additional resistance support for repaired esophageal hiatus, as well as safety of the reconstruction zone, decreasing the recurrence risk $[45,46$, $47,48]$. In this context in the literature there are a lot of biologic materials used for this purpose in the adult surgery [49], including human acellular dermal matrix [50, 51], porcine small bowel submucosa [52]. However this problem is discussed rarely in pediatric surgery [53].

It is considered that antireflux procedure is a key element in the surgical treatment of $\mathrm{HH}$, including paraesophageal hernias, because of the fact that anatomic and physiologic mechanisms of prevention of the gastroesophageal reflux are disturbed in this pathology [22, 54]. In children the Nissen $360^{\circ}$ complete fundoplication is the gold standard, being the most frequent antireflux procedure used in the surgical treatment of gastroesophageal reflux [43]. As an alternative the partial antireflux procedures are proposed, including Toupet $270^{\circ}$ posterior fundoplication, and anterior fundoplications on $180^{\circ}, 120^{\circ}$ and $90^{\circ}$. Techniques of partial anterior fundoplication differ from each other in terms of anchoring of the gastric fornix to the right diaphragmatic crus [55]. The most used are Thal [56, 57], Boix-Ochoa [58] and Watson [59] techniques of partial anterior fundoplication. In paraesophageal $\mathrm{HH}$ the advantage of partial fundoplication is the reduction of the risk of postoperative dysphagia, as well as anchoring of the gastric fornix to the right crus provides a support and stability of the hiatal reconstruction [60].

The recurrence rate of the congenital paraesophageal hernias is around $1,1 \%$, the mortality rate varies between 0 and $20 \%$ and strongly depends on the associated comorbidities [60].

\section{Conclusions}

Type III paraesophageal hiatal hernia is a rare diagnosis, that could be identified incidentally because of the asymptomatic evolution, and a careful differential diagnosis, including thoracic cysts is needed. The partial torsion of the stomach that could be found in this mixed form of hiatal hernias has a high risk of severe complications development, which is a strong reason for 
planned surgery if the diagnosis is confirmed. Using of equine pericardial acellular grafts could be a suitable option for the hiatal defect repairing in paraesophageal hiatal hernias in children, but this technique needs an adequate follow-up regimen.

\section{References}

1. Oleynikov D, Jolley JM. Paraesophageal hernia. Surg. Clin. N. Am. 2015. 95:555-65.

2. Rochefort M, Wee JO, Management of the difficult hiatal hernia. Thorac. Surg. Clin. 2018; 28:533-9.

3. Özdemir Ö, Keleş D. A baby with hiatal hernia presenting with severe iron-deficiency anemia. Turk. Pediatr. Ars. 2019; 54(1): 66-7.

4. Andolfi C, Jalilvand A, Plana A, Fisichella PM. Surgical treatment of paraesophageal hernias: a review. J. Laparosc. Adv. Surg. Techn. 2016; 26(10):778-783.

5. Mitiek MO, Andrade RS. Giant hiatal hernia. Ann. Thorac. Surg. 2010; 89:S2168-73.

6. Yousef Y, Lemoine C, St-Vil V, Emil S. Congenital paraesophageal hernia: The Montreal experience. J. Pediatr. Surg. 2015; 50:1462-6.

7. Au Yeung KJ, Cannon ML, Arkachaisri T, Gillespie S, Karnsakul W. Impact of hiatal hernia on pediatric gastroesophageal reflux disease. J. Gastrointest. Dig. Sys. 2015; 5:5. DOI: 10.4172/2161-069X.1000330.

8. Dean C, Etienne D, Carpentier B, Gielecki J, Tubbs RS, Loukas M. Hiatal hernias. Surg. Radiol. Anat. 2012; 34:291-9.

9. Kahrilas PJ, Kim HC, Pandolfino JE. Approaches to the diagnosis and grading of hiatal hernia. Best Pract. Res. Clin. Gastroenterol. 2008; 22(4):601-16.

10. Bradley T, Stephenson J, Drugas G, Avansino JR. Laparoscopic management of neonatal paraesophageal hernia with intratoracic gastric volvulus. J. Pediatr. Surg. 2010; 45:E21-E23.

11. Haug HM, Johnson E, Mala T, Forland DT, Sovik TT, Johannessen HO. Incarcerated paraesophageal hernia complicated by pancreatic damage and unusual comorbidity: Two retrospective case series. Int. J. Surg. Case Rep. 2019; 54:75-8.

12. Dipali RB, Kothari PR, Sarda DK, Desai N, Shanbhag P. Congenital paraesophageal hernia presenting with severe gastroesophageal reflux. Indian J. Pediatr. 2007; 74(3):310-1.

13. Munteanu AC, Munteanu M, Ruxandru A, Şurlin V. Type III mixt hiatal hernia, a rare variant with severe complications. J. de chirur. (Iaşi). 2012; 8(1): 69-74.

14. Namgoong JM, Kim DY, Kim SC, Hwang JH. Hiatal hernia in pediatric patients: laparoscopic versus open approaches. Ann. Surg. Treat. Res. 2014; 86(5):264-9.

15. Banimostafavi ES, Tayebi M. Large hiatal hernia with pancreatic body herniation: Case-report. Ann. Med. Surg. 2018; 28:20-2.
16. Başaklar AC, Sonmez K, Karabulut R. An unusual case: a giant paraesophageal hiatal hernia with intratoracic spleen, produodenal portal vein, malrotation, and left inferior vena cava. J. Pediatr. Surg. 2007; 42:E23-E25.

17. Patel S, Shahzad G, Jawaira M, Subramani K, Viswanathan P, Mustacchia P. Hiatus hernia: a rare cause of acute pancreatitis. Case Rep. med. 2016; 2016:2531925. doi: 10.1155/2016/2531925.

18. Sadi A. Abukhalaf, Adham M, Muath A. Baniowda, Rami A, Radwan A. Giant hiatal hernia with pancreas herniation. Open Access J. Surg. 2019; 10(5): 555800. DOI: 10.19080/OAJS.2019.10.555800.

19. Wongrakpanich S, Hassidim H, Chaiwatcharayut W, Manatsathit W. A case of giant hiatal hernia in an elderly patient: When stomach, duodenum, colon, and pancreas slide into thorax. J. Clin. Gerontol. \& Geriatr. 2016; 7:112-4.

20. Carrott PhW., Hong J, Kuppusamy MK, Kirtland S, Koehler RP, Low DE. Repair of giant paraesophageal hernias routinely produces improvement in respiratory function. J. Thorac. Cardiovasc. Surg. 2012; 143:398404.

21. Avansino JR, Lorenz ML, Hendrickson M, Jolley SG. Characterization and management of paraesophageal hernias in children after antireflux operation. J. Pediatr. Surg. 1999; 34:1610-4.

22. Karpelowsky JS, Wieselthaler N, Rode H. Primary paraesophageal hernia in children. J. Pediatr. Surg. 2006; 41:1588-93.

23. Cho MJ, Nam CW, Lee SJ, Lim G, Oh KW. Prenatal diagnosis of congenital paraesophageal henia. J. Pediatr. Surg. Case Rep. 2018; 32:32-4.

24. Imamoglu M, Cay A, Kossucu P, Osdemir O, Orhan F. Congenital paraesophageal hiatal hernia: pitfalls in the diagnostic treatment. J. Pediatr. Surg. 2005. 40:112833.

25. Jang WN, Park IS, Park KW, Yoo SY, Lee J, Cho SH. A case of congenital paraesophageal hiatal hernia in infancy. Pediatr. Gastroenterol., Hepatol.\& Nutr. 2012; 15(2):100-4.

26. Al-Salem AH. Congenital paraesophageal hernia with intratoracic gastric volvulus in two sisters. ISRN Surg. 2011. Art. ID 856568. 5 p. Doi: 10.5402/2011/856568.

27. Rees JE., Robertson S, McNinch AW. Congenital paraoesophageal hiatus hernia: an interesting family history. Emerg. Med. J. 2004; 21:749-50. 
28. Chan KJ, Smithers BM, Hii MW. Giant hiatus hernia and association with gastro-oesophageal reflux: A review. J. Clin. Gastroenterol. Treat. 2017; 3(2):045. Doi:10.23937/2469-584x/151004.

29. Garvey EM, Ostlie DJ. Hiatal and paraesophageal hernia repair in pediatric patient. Semin. Pediatr. Surg. 2017; 26:61-6.

30. Stylopoulos N, Rattner DW. The history of hiatal hernia surgery. Ann. Surg. 2005; 241(1):185-93.

31. Johnston JH. Hiatus hernia in childhood. Arch. Dis. Child. 1960; 35:61-5.

32. Akhmatov AM, Tarbaev IS, Vasilevsky DI. The history of development of hiatal hernias surgery. Pediatr. 2018; 9(3):77-80.

33. Van Niekerk ML. Laparoscopic treatment of type III para-oesophageal hernia. SAIS. 2011; 49(1):47-8.

34. Arlikar J, McKay V, Danielson P. Association of congenital diaphragmatic hernia and hiatal hernia with tetrasomy 18pq. J. Pediatr. Surg. Case Rep. 2014; 2:309-12.

35. Miyagi H, Honda S, Hamada H, Minato M, Ara MW, Taketomi A. One-stage laparoscopic surgery for pulmonary sequestration and hiatal hernia in a 2-yearold girl. Eur. J. Pediatr. Surg. 2018; 6:e11-e14.

36. Gorla SR, Fernandez-Sanchez J, Garg A, Swaminathan S. Unilateral lung agenesis, hiatal hernia and atrioventricular septal defect: a rare combination of congenital anomalies. BMJ Case Rep. 2018. pii:bcr2018-224382. doi:10.1136/bcr-2018-224382.

37. Tsai J, Blinman TA, Collins JL, Laje P, Hedrick HL. The contribution of hiatal hernia to severe gastroesophageal reflux disease in patients with gastroschisis. J. Pediatr. Surg. 2014; 49(3):395-8.

38. Kunisaki SM, Dakhoub A, Jarboe MD. Gastric dissociation for the treatment of congenital microgastria with paraesophageal hiatal hernia. J. Pediatr. Surg. 2011; 46:E1-4

39. Lugaresi M, Mattioli S, Aramini B, D’Ovidio F, Di Simone MP, Perron O. The frequency of true short oesophagus in type II-IV hiatal hernia. Eur. J. CardioThor. Surg. 2013; 43:e30-e36.

40. Samiullah Ishtiaq S, Taimur M. Strangulated paraesophageal hiatus hernia: a case report. ISRA Med. J. 2015; 7(3):171-4.

41. Patoulias D, Kalogirou M., Feidantsis T, Kallergis I., Patoulias I. Paraesophageal hernia as a cause of chronic asymptomatic anemia in a 6 years old boy; Case report and review of the literature. Arta Medica. 2017; 60(2):76-81.

42. Tamene A, Mela M. A large hiatal hernia with cameron ulcer presenting as refractory sever iron deficiency anemia: a case report. J. Pediatr. Surg. Case Rep. 2018; 37:16-9.

43. Petrosyan M, Shah AA, Chahine AA, Guzzetta PhC, Sandler AD, Kane TD. Congenital paraesophageal hernia: Contemporary results and outcomes of laparoscopic approach to repair in symptomatic infants and children. J. Pediatr. Surg. 2019. 54:1346-50.

44. Davis SS. Current controversies in paraesophageal hernia repair. Surg. Clin. N. Am. 2008; 88:959-78.

45. Oelschlager BK, Pellegrini CA, Hunter JG, Brunt ML. Soper N.J. et al. Biologic prosthesis to prevent recurrence after laparoscopic paraesophageal hernia repair: long-term follow-up from a multicenter, prospective, randomized trial. J. Am. Coll. Surg. 2011; 213:461-8.

46. Reznichenko AA. Different biologic grafts for diaphragmatic crura reinforcement during laparoscopic repair of large hiatal hernia: A six-year single surgeon experience. J. Curr. Surg. 2016; 6(1):6-13.

47. Schmidt E, Shaligram A, Reynoso JF., Kothari V, Oleynikov D. Hiatal hernia repair with biologic mesh reinforcement reduces recurrence rate in small hiatal hernias. Dis. Esoph. 2014; 27(1):13-7.

48. Wang WP, Yang YS, Shang QX, Chen LQ. Prosthetic mesh use for esophageal hiatal hernia repair. Biomed. J. Sci. \&Tech. Res. 4(4)- 2018. BJSTR. MS.ID.001083. DOI: 10.26717/ BJSTR.2018.04.001083

49. Sasse KC, Warner DL, Ackerman E, Brandt J. Hiatal hernia repair with novel biological graft reinforcement. JSLS. 2016; 20(2):e2016.00016. doi: 10.4293/JSLS.2016.00016.

50. Diaz DF, Roth JS. Laparoscopic paraesophageal hernia repair with acellular dermal matrix cruroplasty. JSLS. 2011;15:355-60.

51. Ringley CD, Bochkarev V, Ahmed SI, Vitamvas ML, Oleynikov D. Laparoscopic hiatal hernia repair with human acellular dermal matrix patch: our initial experience. Am. J. Surg. 2006; 192:767-72.

52. Oelschlager BK, Barreca M, Chang L. The use of small intestine submucosa in the repair of paraesophageal hernias: Initial observations of a new technique. Am. J. Surg. 2003; 186:4-8.

53. St Peter SD, Ostlie DJ, Holcomb III GW. The use biosynthetic mesh to enhance hiatal repair at the time redo Nissen fundoplication. J. Pediatr. Surg. 2007; 42:1298-1301.

54. Schieman C, Grondin SC. Paraesophageal hernia: Clinical presentation, evaluation, and management controversies. Thorac. Surg. Clin. 2009; 19:473-84.

55. Watson DI, Devitt PG, Smith L, Jamieson G.G. Anterior $90^{\circ}$ partial vs Nissen fundoplication -5 year 
follow-up of a single-centre randomised trial. J. Gastrointest. Surg. 2012; 16:1653-8.

56. Kubiak R, Bohm-Sturm E, Swoboda D, Wessel L. Comparison of long-term outcomes between open and laparoscopic Thal fundoplication in children. J. Pediatr. Surg. 2014; 49:1069-74.

57. Wafa TA, El-Saied A, Dessouky NM, El-Ghazaly M, Barakat T. Laparoscopic Thal versus laparoscopic Nissen fundoplication in children: comparative study regarding outcome and patient satisfaction. Ann. Pediatr. Surg. 2017; 13:74-7.
58. Menon SS, Sarma VP, Sivakumar K, Hema R. BoixOchoa anti reflux procedure: an institutional experience. JMSCR. 2018; 6(9):137-9.

59. Dunckley MG, Rajwani KM, Mahomed AA. Laparoscopic Watson fundoplication is effective and durable in children with gastroesophaeal reflux. HPC. Min. Inv. Surg. 2014. Art. ID 409727. 4 p. http://dx.doi.org/10.1155/2014/409727.

60. Collet D, Luc G, Chiche L. Management of large paraesophageal hiatal hernias. J. Visceral Surg. 2013; $150: 395-402$..

\section{Correspondence to:}

Victor Eremia

93Burebista MD-2062

Chișinău, Republica Moldova

Phone: (22) 521171

E-mail: eremiavictor1@gmail.com 